\title{
Is Parental Death a Selective Precursor to Either Panic Disorder or Agoraphobia?
}

\author{
A Test of the Separation Anxiety Hypothesis
}

\author{
Bruce A. Thyer, Ph.D. \\ University of Georgia \\ JoSePh Himle, M.S.W., AND DANIEl Fischer, M.S.W. \\ University of Michigan
}

\begin{abstract}
In a controlled chart-review study of the separation anxiety hypothesis (SAH) of agoraphobia or panic disorder, the incidence of parental (maternal and paternal) deaths was recorded from the histories of 40 patients, each with panic disorder, agoraphobia, and a control group of simple phobics. The overall incidence of parental loss was low in all three groups, and there were no significant differences among them either in terms of the incidence of parental death or in patient ages at the time of parental death. It is concluded from these results and on a review of other studies on the SAH that the hypothesis is not well supported and should be abandoned in the DSM-IV.
\end{abstract}

It is often contended in the psychiatric and psychological literature on anxiety disorders that parental loss is a specific precursor to some conditions. For example, the DSM-III (American Psychiatric Association, 1980) states that for both agoraphobia and panic disorder, "Separation anxiety disorder in childhood and sudden object loss apparently predispose to the development ... (of these conditions)" (pp. 226, 231). This 'separation anxiety hypothesis' (SAH) has been modified in the DSMIII-R to read, "Separation anxiety disorder in childhood and sudden loss of social support or disruption of important interpersonal relationships apparently predisposes to the development of ... [panic disorder or panic disorder with agoraphobial" (American Psychiatric Association, 1987 , p. 237). In turning to the DSM-III-R description of separation anxiety disorder, the document reads that "In most cases the disorder develops after some life stress, typically a loss, the death of a relative . .." (American Psychiatric Association, 1987, p. 60).

This separation anxiety hypothesis for panic disorder and agoraphobia seems intuitively compelling, given the apparent similarities between the

Address correspondence and reprint requests to Bruce A. Thyer, Ph.D., School of Social Work, University of Georgia, Athens, GA, 30602. 
fearful reactions of children suffering from separation anxiety disorder when apart from their significant caregivers, and the acutely anxious or dependent behaviors of panic disorder patients or agoraphobic adults. The SAH for panic disorder and agoraphobia is not a clinically unimportant point for academicians to debate, since its largely uncritical acceptance is beginning to have an impact upon the treatment literature related to these conditions (Friedman, 1985).

A number of reviews of empirical research on the validity of the SAH have recently been conducted by Thyer and associates (Thyer, in press; Thyer, Nesse, Cameron, \& Curtis, 1985; Thyer, Nesse, Curtis, \& Cameron, 1986). The evidence supporting the view that panic disorder and/ or agoraphobia are etiologically related or, more simply investigated, preceded by childhood or adolescent separation anxiety, is methodologically quite weak. Many studies were anecdotal in nature, uncontrolled, subject to interviewer bias, or employed poorly validated diagnostic criteria (Frances \& Dunn, 1975; Klein, 1964; Klein \& Fink, 1962; Mendel \& Klein, 1969; Rhead, 1969; Roth, 1959; Stamm, 1972; Wangh, 1967). A number of empirical investigations seem to refute the SAH (Deltito, Perugi, Maremmani, Mignani, \& Cassano, 1986; Thyer et al., 1985, 1986), and a recent, reasonably well controlled study by early advocates of the SAH, Gittelman and Klein $(1984,1985)$, found evidence in favor of the SAH only for female agoraphobics, not for male patients.

It is evident that the data pertaining to the SAH of panic disorder and agoraphobia, which postulates that such patients are likely to have experienced conditions such as childhood separation anxiety disorder, school phobia, parental death or other object loss, and so forth, are conflictual. Given the relative lack of empirical and unambiguous support for the $\mathrm{SAH}$, it is puzzling to note that the DSM-III-R continues to perpetuate it. As noted earlier, ". . . careful consideration should be given to including this hypothesis in subsequent (diagnostic) formulations, unless better evidence is found" (Thyer et al., 1985, p. 77). To date, the evidence remains quite weak, and given the purported atheoretical and empirical foundations of the DSM-III-R (American Psychiatric Association, 1987), we conducted the following investigation as a further and relatively robust test of one aspect of the SAH.

\section{METHOD}

\section{Patients and Dependent Variables}

Data for this study were extracted from patient records of individuals who had been evaluated at the Anxiety Disorders Program of the Department of Psychiatry at the University of Michigan, and who had received their diagnosis from a clinician skilled in the use of the DSM-III criteria. Forty patients each were randomly selected from all patients diagnosed as meeting the criteria for either panic disorder, agoraphobia with panic attacks, or simple phobia (in the absence of a history of spontaneous panic attacks). Basic demographic information was culled from each pa- 
tient's chart, including age at intake, age at onset of the respective anxiety disorder, information pertaining to maternal and paternal deaths (if any), and the patient's age at the time the death(s) occurred. This information pertaining to parental death and patient age is given by each patient on our clinic's intake forms. Our dependent variables thus involve the frequency of parental deaths between the three diagnostic groups, and these patients' ages at the time at which such deaths occurred. This study was intentionally designed to support or refute the following two research hypotheses, derived from the DSM-III-R (American Psychiatric Association, 1987, p. 237).

\section{Hypothesis 1}

The panic disorder and agoraphobic patient groups will report a significantly greater frequency of parental deaths than the comparison group of simple phobic patients.

\section{Hypothesis 2}

Parental deaths occurring among the panic disorder or agoraphobic groups will have occurred significantly earlier than those of the simple phobic patients.

Our choice of parental death and patient age at the time of such deaths as our dependent variables was made on the basis of the relative accuracy with which we believe patients report such events, avoiding the problems associated with retrospectively diagnosing adult patients based upon their recall of childhood symptomatology, and of the biases associated with nonblind structured interviews. Hypothesis 2 was formed on the assumption that earlier loss of a parent is more likely to be pathogenic than experiencing the death of a parent as an adult.

We believe that a control group of simple phobic patients provides a more robust test of the SAH of panic disorder or agoraphobia than the use of normal nonpatient matched controls for several reasons. When using matched controls, unintended biases on the part of the researchers may effect the matching process. Our use of randomly selected charts from a much larger pool of simple phobic patients avoids the potential for such bias. Secondly, the SAH is now purportedly a specific precursor only to panic disorder and its variants, and to no other disorder, presumably because of the psychodynamic or biological theories relating childhood separation anxiety and adult panic attacks, and the similarities in the symptomatic picture for the two conditions. The use of a clinically anxious comparison group, one with no known history of panic attacks, provides a scientifically more robust test of our hypotheses.

\section{RESULTS}

Demographic data for the three groups of subjects are presented in Table 1. Patients in the three groups were not found to differ in their mean 
TABLE 1

Selected Demographic Characteristics of Three Patient Groups

\begin{tabular}{|c|c|c|c|c|c|c|}
\hline \multirow[b]{2}{*}{ Diagnosis } & \multirow[b]{2}{*}{$n$} & \multirow{2}{*}{$\begin{array}{c}\% \\
\text { Female }\end{array}$} & \multicolumn{2}{|c|}{$\begin{array}{l}\text { Age at } \\
\text { Intake }\end{array}$} & \multicolumn{2}{|c|}{$\begin{array}{l}\text { Age at } \\
\text { Onset }\end{array}$} \\
\hline & & & $M$ & $S D$ & $M$ & $S D$ \\
\hline Simple Phobia & 40 & 68 & 37.0 & $(11.0)$ & 20.7 & $(13.7)$ \\
\hline Panic Disorder & 40 & 45 & 35.1 & $(10.3)$ & 25.5 & $(10.0)$ \\
\hline Agoraphobia & 40 & 78 & 34.2 & $(8.1)$ & 24.6 & $(8.9)$ \\
\hline
\end{tabular}

ages at intake. Our simple phobic group was comprised of significantly more women than the panic disorder or agoraphobic groups. Data pertaining to parental deaths experienced by the patients in the three diagnostic groups is reported in Table 2 . No significant differences occurred between the three patient groups on this variable. Data pertaining to patients' ages at the time of parental deaths is presented in Table 3. Again, no significant differences emerged. Thus, neither of our two research hypotheses was supported by our findings. Missing data relating to patient age at the time of parental death accounts for the discrepancies in the $n \mathrm{~s}$ appearing in Tables 2 and 3.

\section{DISCUSSION}

A major virtue of chart review studies of this nature is their relative simplicity. If parental death were a significant and selective precursor to the development of agoraphobia or panic disorder, we believe our study would have detected it. Our failure to find the predicted relationships leads us once again to question the validity of the SAH as embodied in its latest incarnation in the DSM-III-R, insofar as the variable of parental death, a purported precursor to $\mathrm{SAH}$, is concerned. The majority of related investigations testing this hypothesis have failed to support it; those which corroborate it suffer from serious methodological flaws or yield statistically significant findings that account for only a small proportion of explained variance. Future researchers using adult-patient-provided

TABLE 2

STATUS OF PARENTS

\begin{tabular}{lccccc} 
& \multicolumn{3}{c}{ Mother* } & & \multicolumn{2}{c}{ Father** $^{*}$ Diagnosis } & Alive & Dead & & Alive & Dead \\
\cline { 2 - 3 } & 33 & 7 & 22 & 18 \\
Simple Phobia & 33 & 7 & & 26 & 14 \\
Panic Disorder & 37 & 3 & & 25 & 15 \\
Agoraphobia & & & &
\end{tabular}

$\chi^{2}(2)=2.19 ; p=.33$

$* * \chi^{2}(2)=.90 ; p=.63$ 
TABLE 3

Patient Age (In years) at Time of Parental Death

\begin{tabular}{lccccccr}
\hline & \multicolumn{3}{c}{ Maternal Death* } & & \multicolumn{3}{c}{ Paternal Death** } \\
\cline { 2 - 4 } \cline { 6 - 8 } Diagnosis & $n$ & $M$ & $S D$ & & $n$ & $M$ & $S D$ \\
\hline Simple Phobia & 7 & 40.9 & 11.9 & & 18 & 32.6 & 15.3 \\
Panic Disorder & 5 & 35.6 & 14.5 & & 11 & 28.5 & 9.2 \\
Agoraphobia & 3 & 35.3 & 11.2 & & 14 & 24.9 & 10.2 \\
\hline
\end{tabular}

$F(2,12)=.33 ; p=.72$

$* * F(2,40)=1.50 ; p=.23$

historical data to make retrospective diagnoses of childhood separation anxiety disorder or school phobia should collect such information using blind interviewers, and provide reliability and validity data concerning their diagnostic procedures, as is now a common practice in related fields.

A final point to be made is that contemporary evidence indicates that parental death does not appear to be a specific precursor to other, more severe, mental disorders such as psychoses, depression, or bipolar disorder (Pfohl, Stangl, \& Tsuang, 1983; Ragan \& McGlashan, 1986). This suggests that its etiological role in less severe conditions such as the anxiety disorders is similarly minimal. Until well controlled studies involving validated dependent variables and large effect sizes clearly document the soundness of the SAH, we believe that the most scientifically credible position is that the null hypothesis should be retained. There is no good evidence that parental death, object loss, or a history of separation anxiety disorder or school phobia uniquely disposes one to the development of panic disorder or agoraphobia. Unless clear evidence to the contrary emerges, we hope that the projected DSM-IV discards the separation anxiety hypothesis.

\section{REFERENCES}

American Psychiatric Association. (1980). Diagnostic and statistical manual of mental disorders (3rd ed.). Washington, DC: Author.

American Psychiatric Association. (1987). Diagnostic and statistical manual of mental disorders (3rd ed., rev.). Washington, DC: Author.

Deltito, J. A., Perugi, G., Maremmani, I., Mignani, V., \& Cassano, G. B. (1986). The importance of separation anxiety in the differentiation of panic disorder from agoraphobia. Psychiatric Developments, 3, 227-236.

Frances, A., \& Dunn, P. (1975). The attachment-autonomy conflict in agoraphobia. International Journal of Psychoanalysis, 56, 435-439.

Friedman, S. (1985). Implications of object-relations theory for the behavioral treatment of agoraphobia. American Journal of Psychotherapy, 39, 525-540.

Gittelman, R., \& Klein, D. F. (1984). Relationship between separation anxiety and agoraphobic disorders. Psychopathology, 17(Suppl. 1), 56-65. 
Gittelman, R., \& Klein, D. F. (1985). Childhood separation anxiety and adult agoraphobia. In A. N. Tuma \& J. S. Maser (Eds.), Anxiety and the anxiety disorders (pp. 389-402). Hillsdale, NJ: Lawrence Erlbaum.

Klein, D. F. (1964). Delineation of two drug-responsive anxiety syndromes. Psychopharmacologia, 5, 397-408.

Klein, D. F., \& Fink, M. (1962). Psychiatric reaction patterns to imipramine. American Journal of Psychiatry, 119, 432-438.

Mendel, J., \& Klein, D. F. (1969). Anxiety attacks with subsequent agoraphobia. Comprehensive Psychiatry, 10, 190-195.

Pfohl, B., Stangl, D., \& Tsuang, M. T. (1983). The association between early parental loss and diagnosis in the lowa 500. Archives of General Psychiatry, 40, 965-967.

Ragan, P. V., \& McGlashan, T. H. (1986). Childhood parental death and adult psychopathology. American Journal of Psychiatry, 143, 153-157.

Rhead, C. (1969). The role of pregenital fixations in agoraphobia. Journal of the American Psychoanalytic Association, 17, 848-861.

Roth, M. (1959). The phobic anxiety-depersonalization syndrome. Proceedings of the Royal Society of Medicine, 52, 587-595.

Stamm, J. (1972). Infantile trauma, narcissistic injury, and agoraphobia. Psychiatric Quarterly, 46, 254-272.

Thyer, B. A. (in press). Childhood separation anxiety and adult-onset agoraphobia: A review of the evidence. In C. G. Last (Ed.), Anxiety across the lifespan: A developmental perspective on anxiety and the anxiety disorders. New York: Springer.

Thyer, B. A., Nesse, R. M., Cameron, O. G., \& Curtis, G. C. (1985). Agoraphobia: A test of the separation anxiety hypothesis. Behaviour Research and Therapy, 23, 75-78.

Thyer, B. A., Nesse, R. M., Curtis, G. C., \& Cameron, O. G. (1986). Panic disorder: A test of the separation anxiety hypothesis. Behaviour Research and Therapy, 24, 209-211.

Wangh, M. (1967). Psychoanalytic thought on phobia: Its evolution and its relevance for therapy. American Journal of Psychiatry, 123, 1075-1080. 